\title{
The Cholinergic-Regulated Thalamocortical Imagining as Mind Differentiated in Two Phases of Sleep: A View from the Guangdong People
}

\author{
Zi-Jian Cai \\ CaiFortune Consulting, Suzhou, China \\ Email: hrsh8@126.com
}

How to cite this paper: Cai, Z.-J. (2017) The Cholinergic-Regulated Thalamocortical Imagining as Mind Differentiated in Two Phases of Sleep: A View from the Guangdong People. Open Access Library Journal, 4: e3748.

https://doi.org/10.4236/oalib.1103748

Received: June 20, 2017

Accepted: July 4, 2017

Published: July 12, 2017

Copyright $\odot 2017$ by authors and Open Access Library Inc.

This work is licensed under the Creative Commons Attribution International License (CC BY 4.0).

http://creativecommons.org/licenses/by/4.0/

(c) (i) Open Access

\begin{abstract}
Recently, many achievements on neural sciences have been made by the people in television, such as the adipose cause of male hypothalamic aging, and so on. In this article, it is reported that, on June 17 this year in evening in television, the people in Guangdong attending the Opening Ceremony of BRICS Games there suggested that the cholinergic-regulated thalamocortical activation would result in the cortical imagining in mind in sleep. In slow wave sleep, due to the inhibition of thalamic intralaminar nuclei, it would cause the thalamocortical spindle and random free imagining in mind away from the environment by the remaining weak cholinergic activity. In rapid eye movement sleep, due to the activation of the nonspecific thalamic intralaminar nuclei, it would cause the desynchronized dream with conscious attention and imagination in mind by the saliently active cholinergic system. It is thus simply demonstrated the secret of mind in sleep that many people are interested in, which is perspective in application to hypnosis and psychoanalysis.
\end{abstract}

\section{Subject Areas}

Neurology, Neuroscience, Psychiatry \& Psychology

\section{Keywords}

Cholinergic, Thalamocortical Spindle, Slow Wave Sleep, Hypnosis, Thalamic Intralaminar Nuclei, Desynchronized Sleep, Psychoanalysis

\section{Introduction}

Recently, due to the propagation of internet, the literature on science and tech- 
nology has been available to the people. Therefore, the people in television are seriously concerned about the important progressions of science and technology. In addition, the people in television may further propose some mechanisms to solve the difficult problems on natural sciences, with unsolved problems on neuroscience among the hottest topics attracting the people.

The hypotheses on neuroscience recently proposed by the people in television include: (1) In December 2015, citing the wind in causing aging I felt earlier than the people, I proposed that it could influence slow wave sleep, and therefore cause senescence. In 2016, I published a paper proposing that the skin senescence would result in the senescent degeneration of hypothalamic suprachiasmatic nucleus (SCN) [1]. On July 5 in 2016, in television I saw the European people had in parallel speculated in their local time one day earlier the male senescent pathway from adipose accumulation to reduction of sperm to degeneration of hypothalamic preoptic area (POA), very similar. In 2017, I published a paper, introducing, reviewing and supporting the European people in television and their views [2]. Because the aging mechanisms are related to the longevity of human life, their significance of application is more prospective than the theory of evolution and the DNA double helix. (2) On May 7, 2016, from television I saw that one day before on the local time of USA the NBA athletes had considered that the sympathetic nerves perceiving the noxious stimulus and then constricting the blood vessels might be the mechanism of pain sensation. In that year, I published a paper, introducing, reviewing and supporting the US sportsmen in television and their hypothesis [3].

In this article, it is reported by the witness of the author that the Guangdong people in television tried to propose a solution to reveal the secret of mind in sleep.

\section{The Hypothesis by the Guangdong People}

On June 17, 2017, in evening in television, the people in Guangdong attending the Opening Ceremony of BRICS Games held in Guangzhou suggested that the cholinergic-regulated forebrain activation should result in the thalamocortical imagining in mind during sleep. In slow wave sleep, because the thalamic intralaminar nuclei were inhibited, it manifested as the thalamocortical spindle and random free imagining in mind away from the environment. In rapid eye movement sleep, because the nonspecific thalamic intralaminar nuclei were activated, it manifested as the desynchronized thalamocortical dream with conscious attention and imagination in mind. In this article, it is further added many lines of evidence from literature to depict and support this view of Guangdong people. It is thus expected to demonstrate the secret of mind in sleep that many people are interested in.

\section{The Supporting Evidence}

There are many lines of evidence in support of this new hypothesis from the Guangdong people in television. They are mainly categorized as the followings: 
(1) Besides the low-frequency delta wave, the thalamocortical spindles of higher frequency also often occur during the slow wave sleep [4]. Recently, it has been demonstrated in both humans and animals that the thalamocortical spindles may be increased by the remaining weak cholinergic system then. In humans, it was reported that administration of donepezil, an acetylcholinesterase inhibitor, markedly improved the mental status and incorporated the association of sleep spindles [5]. Besides, in rats it was demonstrated that optical stimulation of cholinergic inputs to the thalamic reticular nucleus (TRN) activated the local GABAergic neurons to promote sleep and generated the spindle oscillations that correlated with slow wave sleep [6]. Obviously, the remaining weak cholinergic activities during slow wave sleep [7] result in the increase in thalamocortical spindles of higher frequency. Because the cholinergic inputs are responsible for generating the various imageries in cortex [7] [8] [9], the remaining weak cholinergic activation of thalamocortical networks during slow wave sleep would cause the random free thalamocortical imagining in mind in slow wave sleep, consistent with the various hypnotic procedures drawing the attention away from the environment.

(2) It is common knowledge that the cholinergic inputs to the forebrain are active during rapid eye movement sleep [7] [10], thereby also causing the thalamocortical imagining in mind in rapid eye movement sleep. It is as well common knowledge that the dreams full of imagination occur during the rapid eye movement sleep [11] [12]. However, in rapid eye movement sleep, the intralaminar thalamic nuclei are activated [13], responsible for coordination of various cortical areas for cognitive, sensory, attentive and motor functions [13], while in slow wave sleep the intralaminar thalamic nuclei are inhibited [13]. In this regard, there would cause the desynchronized thalamocortical dream with conscious attention and imagination in mind during rapid eye movement sleep, in contrast to the random free imagining in mind during slow wave sleep.

In all, these categories of evidence depict and support the view from the Guangdong people in television that the cholinergic-regulated thalamocortical activation would result in two types of thalamocortical imagining in mind differentiated in the two phases of sleep, as in Table 1.

\section{Discussions}

The mental activities during sleep have been the secret problem attracting the

Table 1. Two types of thalamocortical imagining differentiated in two phases of sleep.

\begin{tabular}{ccc}
\hline & Slow wave sleep & Rapid eye movement sleep \\
\hline Cholinergic activity & Low & High \\
Thalamic intralaminar nuclei & Inhibited & Activated \\
Wave form & Slow delta wave + spindle & Desynchronized fast wave \\
Thalamocortical imagining & Weak, free and random & Strong and organized \\
Attention and coordination & No & Yes \\
\hline
\end{tabular}


attention of many people and scientists. In this article, from the view of Guangdong people in television, it is easy to understand that the cholinergic-regulated thalamocortical imaging is the main mental activities during sleep. Due to the difference in the activity of intralaminar thalamic nuclei during the two phases of sleep, the slow wave sleep manifests random free imagining as mental activity, while the rapid eye movement sleep manifests desynchronized dream with conscious attention and imagination. With imagining as the consequence of cholinergic-regulated thalamocortical activities, the Guangdong people in television depict the simple and intuitive solution to the secret mind during sleep.

It is necessary to point out that the random free thalamocortical imagining in slow wave sleep occurs together with the strong slow delta wave. Thus, the imagining may be very weak in slow wave sleep, as compared to that in rapid eye movement sleep. It requires more investigations on this neglected topic along with hypnosis in future.

It is important to note that the simplicity of solution would impact on the consideration of other complex phenomena during the two phases of sleep. For the complex mental activities, there are various theories and models for their neural processes, such as memory [14] [15] and language [16]. With this simple mechanism of cholinergic-regulated thalamocortical imaging as the main mental activities during sleep, along with the various theories and models of memory and language, it is possible to incorporate these complex neural processes into the sleep, and to figure out their difference from those during waking.

\section{Brief Perspectives}

The view from Guangdong people in television the cholinergic-regulated thalamocortical imaging as the mind during sleep is perspective in the followings:

1) Due to the intuition and simplicity of the solution, it is easy to explain the secret of mental activities during sleep that many people and scientists feel interested.

2) With this simple solution from Guangdong people in television, it is perspective to improve the various technologies of hypnosis and hypnotic treatments in future, not only relaxing the body, but also guiding the self free imagining away from the environment.

3) Likewise, the Freudian psychoanalysis treats the patients and explains the contents in dreams [17] [18]. With this simple solution from Guangdong people in television, it is also perspective to improve the Freudian psychoanalysis in the future.

\section{Conclusions}

In conclusion, in this article, it introduces a new view raised by the Guangdong people in television attending the Opening Ceremony of BRICS Games held in Guangzhou in the evening on June 17, 2017, suggesting that: (1) The cholinergic-regulated thalamocortical activation should result in the thalamocortical imagining in mind during sleep. (2) In slow wave sleep, as the thalamic intrala- 
minar nuclei were inhibited, it manifested as the thalamocortical spindle and random free imagining in mind away from the environment. (3) In rapid eye movement sleep, as the nonspecific thalamic intralaminar nuclei were activated, it manifested as the desynchronized dream with conscious attention and imagination in mind. In this article, it further collected relevant literatures to depict and support all these three points of view of the Guangdong people in television.

\section{Acknowledgements}

It is herein acknowledged that MingXun Cai paid the Open Access publication fee of this paper.

\section{Conflict of Interest}

The author declares no conflict of interest or financial support for this work.

\section{References}

[1] Cai, Z.-J. (2016) A Hypothetic Aging Pathway from Skin to Hypothalamic Suprachiasmatic Nucleus via Slow Wave Sleep. Sleep Science, 9, 212-215. https://doi.org/10.1016/j.slsci.2016.09.004

[2] Cai, Z.-J. (2017) The Adipose Cause of Senescence of Male Hypothalamic Preoptic Nucleus: An European View. Research \& Reviews. Neuroscience, 1(2), 21-26.

[3] Cai, Z.-J. (2016) The Hypothetic Post-Sensory Nociceptive-Sympathetic Coupling Necessary for Pain Sensation from NBA. Journal of Neurology and Neuroscience, 7, 141. https://doi.org/10.21767/2171-6625.1000141

[4] Himanen, S.L., Virkkala, J., Huhtala, H. and Hasan, J. (2002) Spindle Frequencies in Sleep EEG Show U-shape within First Four NREM Sleep Episodes. Journal of Sleep Research, 11, 35-42. https://doi.org/10.1046/j.1365-2869.2002.00273.x

[5] Ozaki, A., Nishida, M., Koyama, K., Ishikawa, K. and Nishikawa, T. (2012) Donepezil-Induced Sleep Spindle in a Patient with Dementia with Lewy Bodies: A Case Report. Psychogeriatrics, 12, 255-258. https://doi.org/10.1111/j.1479-8301.2012.00411.x

[6] Ni, K.M., Hou, X.J., Yang, C.H., Dong, P., Li, Y., Zhang, Y., Jiang, P., Berg, D.K., Duan, S. and Li, X.M. (2016) Selectively Driving Cholinergic Fibers Optically in the Thalamic Reticular Nucleus Promotes Sleep. eLife, 5, e10382. https://doi.org/10.7554/elife.10382

[7] Szymusiak, R. (1995) Magnocellular Nuclei of the Basal Forebrain: Substrates of Sleep and Arousal Regulation. Sleep, 18, 478-500.

https://doi.org/10.1093/sleep/18.6.478

[8] Porte, H.S. (2013) From Freud to Acetylcholine: Does the AAOM Suffice to Construct a Dream? Behavioral and Brain Sciences, 36, 626-628; https://doi.org/10.1017/S0140525X13001416

[9] van Wijk, B.C., Litvak, V., Friston, K.J. and Daffertshofer, A. (2013) Nonlinear Coupling between Occipital and Motor Cortex during Motor Imagery: A Dynamic Causal Modeling Study. Neuroimage, 71, 104-113. https://doi.org/10.1016/j.neuroimage.2012.12.076

[10] Platt, B. and Riedel, G. (2011) The Cholinergic System, EEG and Sleep. Behavioural Brain Research, 221, 499-504. https://doi.org/10.1016/j.bbr.2011.01.017

[11] Cai, Z.J. (2016) Progressions of Sleep, Memory and Depression Applicable to Psy- 
choanalysis: A Review. Current Psychiatry Reviews, 12, 240-245.

https://doi.org/10.2174/1573400512666160610083505

[12] Cai, Z.J. (2017) Two Types of REM Sleep: The Atonic and Brain REM Sleep. Sleep and Hypnosis, 19, 1-9.

[13] Van der Werf, Y.D., Witter, M.P. and Groenewegen, H.J. (2002) The Intralaminar and Midline Nuclei of the Thalamus. Anatomical and Functional Evidence for Participation in Processes of Arousal and Awareness. Brain Research Reviews, 39, 107 140. https://doi.org/10.1016/S0165-0173(02)00181-9

[14] Warrington, E.K. and Weiskrantz, L. (1982) Amnesia: A Disconnection Syndrome? Neuropsychologia, 20, 233-248. https://doi.org/10.1016/0028-3932(82)90099-9

[15] Cai, Z.J. (1990) The Neural Mechanism of Declarative Memory Consolidation and Retrieval: A Hypothesis. Neuroscience \& Biobehavioral Reviews, 14, 295-304. https://doi.org/10.1016/S0149-7634(05)80039-9

[16] Cai Z-J. (2015) Semantic Memory Association, Procedural Grammar Syntax and Episodic Modality Coordination as Three Interactive Neural Processes Organizing Language: A Model. Open Access Library Journal, 2, e1718.

https://doi.org/10.4236/oalib.1101718

[17] Bergmann, M.S. (2008) The Mind: Psychoanalytic Understanding Then and Now. The Psychoanalytic Quarterly, 77, 139-166. https://doi.org/10.1002/j.2167-4086.2008.tb00337.x

[18] Wikipedia (2017) Psychoanalysis. https://en.wikipedia.org/wiki/Psychoanalysis

Submit or recommend next manuscript to OALib Journal and we will provide best service for you:

- Publication frequency: Monthly

- 9 subject areas of science, technology and medicine

- Fair and rigorous peer-review system

- Fast publication process

- Article promotion in various social networking sites (LinkedIn, Facebook, Twitter, etc.)

- Maximum dissemination of your research work

Submit Your Paper Online: Click Here to Submit

Or Contact service@oalib.com 